\title{
Construção do Conhecimento em Sala de Aula: enfoque no Ensino por Investigação
}

\section{Knowledge Building in the Classroom: Focus on Research Teaching}

\author{
Georgianna Silva dos Santos 1 , Maria de Fátima Alves de Oliveira 2 \\ ${ }_{1}^{1}$ Mestre em Ensino de Ciências/PPG em Ensino em Biociências e Saúde /LAEFIB/FIOCRUZ; Av. Brasil, Manguinhos, 4365, Rio de Janeiro-RJ, \\ Brasil.E-mail: georgiannas@gmail.com *Autor para correspondência \\ ${ }^{2}$ Docente do PPG em Ensino em Biociências e Saúde /LAEFIB/FIOCRUZ; Av. Brasil, Manguinhos, 4365, Rio de Janeiro-RJ, Brasil. E-mail: \\ bio_alves@yahoo.com.br
}

\author{
Palavras-chave \\ Ensino por Investigação \\ Ensino de Ciências \\ Problematização
}

\begin{abstract}
A aprendizagem das Ciências envolve processos individuais e sociais que através de uma educação problematizadora coloca o aluno como participante ativo no seu processo de aprendizagem. Ao se deparar com situações-problemas que lhes são propostas, espera-se que o aluno estabeleça relações e construa conhecimento próximos até do conhecimento científico. Nessa vertente, o Ensino por Investigação é apontado na literatura como um aporte teórico-metodológico que privilegia a problematização, diferenciando-se das aulas expositivas tradicionais por apresentar uma abordagem de ensino centrada no aluno, no qual ele é protagonista na busca da solução de um problema. Neste artigo, trazemos alguns autores que desenvolvem pesquisas no ambiente educacional com professores e alunos através do Ensino por Investigação, no qual vem se destacando como uma linha de estudo em Educação em Ciências e como abordagem didática nas salas de aulas, relacionando a linguagem e a afetividade como processo de construção do conhecimento.
\end{abstract}

The learning of the sciences involves individual and social processes that through a problematizing education places the student as an active participant in their learning process. When faced with situations-problems that are proposed to him, the student is expected to establish relationships and build up knowledge even of scientific knowledge. In this area, Teaching by Research is pointed out in the literature as a theoretical-methodological contribution that privileges the problematization, differentiating itself from the traditional lectures by presenting a student-centered teaching approach, in which it is protagonist in the search for the solution of a problem. In this article, we bring some authors who develop research in the educational environment with teachers and students through Teaching by Research, in which it has been highlighting as a line of study in Science Education and as a didactic approach in classrooms, relating language and affectivity as a process of knowledge construction.

\section{INTRODUÇÃO}

Para o desenvolvimento deste estudo, recorremos a alguns estudos que discutiam a importância da construção do conhecimento em sala de aula utilizando o Ensino por Investigação. Apesar de diferentes temas e contextos em discussão em pesquisas sobre Ensino de Ciências, as problemáticas que envolvem os conteúdos de Biociências são sempre estudadas de forma desconectadas entre si e com a realidade do aluno. A maior parte dos livros didáticos, por exemplo, existentes no mercado editorial ratifica essa organização estanque, fragmentada e "biologizante" do currículo de Ciências.

Quando autores de livros ousam propor uma coleção com abordagem menos linear e fragmentada, rompendo com a organização tradicional, têm pouco sucesso na adoção pela maioria dos professores, que parecem se sentirem mais seguros em utilizar livros da linha tradicional (WALDHELM, 2007).
A escola deveria, portanto, fomentar situações em que o aluno se visse obrigado a pensar e não a repetir. Numa proposta que utilize a investigação, o aluno deixa de ser apenas um observador das aulas, muitas vezes expositivas, passando a ter grande influência sobre ela, precisando argumentar, pensar, agir, interferir, questionar, fazer parte da construção do seu conhecimento (CARVALHO, 2004). Com isso, o aluno deixa de ser apenas um conhecedor de conteúdos e passa a fazer parte do processo de ensinoaprendizagem.

Corroborando com Mortimer (1992), os alunos possuem uma série de ideias alternativas aos diversos conceitos ensinados durante as aulas de ciências, e estas ideias são pessoais, fixas e difíceis de serem mudadas. O autor argumenta que a permanência dessas ideias com as lições tradicionais de ciências colocou em evidência a necessidade de se construir uma nova perspectiva para o ensino de ciências.

Assim, utilizar atividades investigativas como ponto de 
partida para desenvolver a compreensão de conceitos é uma forma de levar o aluno a participar de seu processo de aprendizagem, sair de uma postura passiva e começar a perceber e agir sobre o seu objeto de estudo (MÁXIMOPEREIRA, 2013). Os próximos tópicos que serão abordados relacionam o processo de construção do conhecimento com a linguagem, a afetividade, envolvendo o Ensino por Investigação.

\section{O Papel da Linguagem na Construção do Conhecimento}

A linguagem no processo de construção do conhecimento é primordial, através das leituras, das diversas linguagens, sejam gráficas ou tabelas, ou a própria linguagem escrita, como também a expressão do aluno, no momento da argumentação, servirá para medir se esse conhecimento está acontecendo ou não. O professor participa desse processo quando ele afere o discurso do aluno, verifica o registro que eles fazem, subsidiando o conhecimento, fornecendo diversas linguagens para que se alcance o conhecimento científico.

No entanto, é importante que o professor ofereça espaço nas suas atividades para os alunos conversarem em grupos, discutirem e elaborarem seus pensamentos ou até mudar de opinião, oferecendo novas evidências para que eles possam incluir isso na sua discussão e tomar posicionamento. Tais abordagens podem ser realizadas tanto pelo professor quanto pelas propostas de atividades, de leituras de textos, de atividades experimentais, de demonstração, de observação, de fenômenos, e assim, vai surgindo novos elementos para que o aluno nas suas interações discursivas em sala de aula construa e reelabore o conhecimento (LOPES SCARPA, 2015).

O procedimento relatado acima, foi observado no texto base desse trabalho, intitulado "Construindo Conhecimento Científico em Sala de Aula" de autoria de Driver e colaboradores (1999), no qual, os autores colocam a aprendizagem das ciências envolvendo processos individuais e sociais. Isso acontece, quando o aluno se depara com situações problemas que ele tem que resolver em grupo especificamente, e é justamente aí que ele vai conseguir estabelecer relações e construir conhecimento próximo até do conhecimento científico, pois, quando o professor oferece atividades diversificadas, oferece possibilidades desses ambientes, dessas situações problemáticas em sala de aula.

\section{Estratégia de Ensino: Ensino Investigativo na prática dos professores de Ciências}

Os problemas no Ensino de Ciências têm sido comentados na literatura e discutidos nos fóruns específicos, como exemplo, temos a ênfase dada aos conteúdos desprovidos de significados no contexto social do aluno; o foco na memorização; o excesso de aulas expositivas e o uso da experimentação como mera ilustração, dissociada de uma estratégia de ensino mais ampla. O aluno que desenvolve capacidade de pensar e de encontrar soluções para os problemas é aquele que realmente aprende a aprender e que pode buscar seus próprios conhecimentos.

Conhecer as concepções dos alunos é fundamental antes de iniciarmos a aula a fim de que eles possam relacionar seus conhecimentos aos conhecimentos científicos. De acordo com Delizoicov et al., (2009) o professor pode contextualizar o conteúdo a ser abordado ao cotidiano do aluno numa linguagem que possa ser entendida por ele, sem recorrer à memorização, adotando em sua prática estratégias de ensino que favorecem a construção do conhecimento.

Quando o professor utiliza atividades que permitem a interação entre os alunos e entre alunos e professor, ocorre a compreensão sobre o conteúdo e os alunos passam de participantes passivos para ativos (FERNANDES, 2011). Utilizar atividades diferenciadas é um recurso importante para promover a aprendizagem de ciências, desde que sejam planejadas para facilitar o desenvolvimento dos conceitos e o interesse pela ciência (ALVES DE LIMA; RIBEIRO; MARCONDES, 2005). Esta forma de pensar está relacionada ao fato de que os conceitos científicos não são aprendidos de modo definitivo durante a educação formal, porque a aprendizagem é um processo em construção contínua.

Para que uma atividade seja considerada investigativa, os alunos devem não somente observar fenômenos e manipular informações ou experimentos, mas também formular hipóteses, refletir e discutir em grupo, explicar os argumentos utilizados e relatar suas conclusões, ou seja, participar de etapas que se assemelham a investigação científica (CHINN; MALHOTRA, 2002; ABEGG; BASTOS, 2005; CARVALHO; SASSERON, 2011). O desenvolvimento de atividades com enfoque no ensino investigativo pressupõe também a existência de uma situação problemática, a fim de possibilitar a aprendizagem e, consequentemente, o desenvolvimento cognitivo do aluno.

Ao utilizar proposta pedagógica investigativa, o professor deve orientar a tarefa de construção e reformulação de conceitos estimulando o diálogo com o conhecimento prévio dos alunos sobre o conteúdo apresentado, a partir da utilização de recursos que facilitem sua compreensão (SASSERON; CARVALHO, 2011). Carvalho (2018) ressalta que a diretriz principal de uma atividade investigativa é o cuidado do (a) professor (a) com o grau de liberdade intelectual dado ao aluno e com a elaboração do problema.

Para a autora, estes dois itens são bastante importantes: 
pois é o problema proposto que irá desencadear o raciocínio dos alunos e sem liberdade intelectual eles não terão coragem de expor seus pensamentos, seus raciocínios e suas argumentações (CARVALHO, 2018, p. 03).

Segundo Abegg e Bastos (2005) a atividade de ensino investigativo dá oportunidade ao professor de trabalhar com situações do cotidiano dos alunos na perspectiva da elaboração e resolução de problemas, que são eixos norteadores da política pública educacional brasileira (BRASIL, 2006). Muitas vezes, o aluno possui conhecimento sobre um tema, possui argumentos sobre as situações, adquiridos com suas experiências, faltando a ele relacionar seu conhecimento ao conhecimento científico.

De acordo com os PCN's é função do docente trazer elementos das teorias científicas para a sala de aula sob a forma de perguntas, indicações para observação e experimentação, leitura de textos e em seu próprio discurso explicativo. Por meio do processo investigativo, com a busca de informações e o confronto de ideias é que o conhecimento científico se constrói (BRASIL, 1998).

Dos Santos e Galembeck (2018), ao desenvolverem uma sequência didática investigativa com alunos do 3 ㅇ e 5 으 ano do Ensino Fundamental de uma escola pública, tinham como objetivo evidenciar as contribuições de estratégias práticas e experimentais, pautadas no ensino por investigação. Os resultados obtidos apresentaram formulações de hipóteses com qualidade, apoiadas em experiências práticas e em conceitos teóricos abordados.

Em outro contexto, Trazi e Brazil (2017) utilizaram os níveis de investigação elaborado por Borges (2002), em aulas de Biologia na perspectiva do Ensino por Investigação com alunos da 1a série do Ensino Médio de uma escola pública estadual de Vitória, Espírito Santo - ES.

Os autores especificaram como as aulas foram avaliados a partir dos 4 níveis que Borges (2002) estabelece como parâmetros investigativos (Quadro 1).

No nível 0 , corresponde aproximadamente ao extremo de 'problema fechado', são dados o problema, os procedimentos e aquilo que se deseja observar/verificar, ficando a cargo dos estudantes coletar dados e confirmar ou não as conclusões.

No nível 1, o problema e procedimento são definidos pelo professor, através de um roteiro, por exemplo. Ao estudante cabe coletar os dados indicados e obter as conclusões.

No nível 2, apenas a situação-problema que é dada, ficando para o estudante decidir como e que dados coletar, fazer as medições requeridas e obter conclusões a partir deles.

No nível 3 - é o mais aberto de investigação - o estudante deve fazer tudo, desde a formulação do problema até chegar às conclusões (BORGES, 2002, p.23).

Após as análises, os autores elaboraram categorias para discutir os resultados encontrados e constataram um:

\begin{abstract}
Caráter parcialmente investigativo da atividade experimental desenvolvida, a qual situa-se no nível 1 , no qual o problema e procedimentos foram definidos pela professora por meio de um questionário de levantamento das hipóteses dos alunos sobre os possíveis resultados de duas situações-problema da atividade; os estudantes coletaram os dados e as conclusões ficaram em aberto para serem obtidas em consenso com a professora (TRAZI; BRAZIL, 2017, p.08).
\end{abstract}

As evidências apontaram que o protagonismo do docente da turma do estudo se mostrou mais acentuado do que o dos alunos e a participação dos estudantes limitou-se mais a seguir as diretrizes da professora.

Nesse contexto, cabe ao professor estimular as discussões, as exposições de ideias, propor novas questões e ajudar os alunos a manterem coerências dessas ideias, realizando diferentes atividades, que devem estar acompanhadas de situações problematizadoras, questionadoras e de diálogo, envolvendo resolução de problemas e levando à introdução de conceitos para que os

Quadro 1: Níveis de Investigação elaborado por Borges (2002)

\begin{tabular}{|l|l|l|l|}
\hline Nível de Investigação & Problema & Procedimentos & Conclusões \\
\hline Nível 0 & Dados & Dados & Dados \\
\hline Nível 1 & Dados & Dados & Em aberto \\
\hline Nível 2 & Dados & Em aberto & Em aberto \\
\hline Nível 3 & Em aberto & Em aberto & Em aberto \\
\hline
\end{tabular}

Fonte: Borges (2002, p. 23). 
alunos possam construir seu conhecimento.

Por outro lado, em uma perspectiva humanista, não somente, um material bem elaborado e/ou uma aula atendendo a proposta investigativa será suficiente, se o aluno não demostrar uma disposição para aprender, ou seja, o aluno deve querer relacionar o novo conhecimento ao seu conhecimento prévio.

\section{Relação Afetividade e Aprendizagem}

A questão de troca de significados deve considerar que seres humanos pensam, sentem e agem e deve ajudar a explicar como se pode melhorar as maneiras através das quais as pessoas fazem isso. Considerar a afetividade no processo de construção de conhecimento envolve, de acordo com Novak, uma ação para trocar significados (pensar) e sentimentos entre aprendiz e professor (MOREIRA, 2012).

As ações humanas são motivadas por algum componente afetivo que a faz acontecer, ou seja, o gatilho de uma ação é a afetividade. Assim, a produção de conhecimento é um processo de intercâmbio e negociação de significados; é uma construção humana que coloca em jogo pensamentos, ações e sentimentos e, nesse sentido, é uma construção que se produz em dadas condições e em um determinado contexto (SANTOS, 2007). Alguns trabalhos (SANTOS, 2007, SANTOS; MORTIMER, 1999) evidenciam a presença da afetividade e aprendizagem ao levar em consideração os aspectos que promovem uma relação mais estimulante dos alunos com o conhecimento científico, no qual, estão relacionados não só à competência discursiva do professor na promoção do processo de significação nas interações em aula ou na contextualização do conhecimento científico.

\section{AGRADECIMENTOS}

CAPES - Pela bolsa de estudos da autora Georgianna Silva dos Santos

\section{CONCLUSÕES}

As ideias informais trazidas para a sala de aula, não são apenas visões pessoais do mundo, mas refletem uma visão comum, representada por uma linguagem compartilhada. Essa visão compartilhada constitui o 'senso comum', uma forma socialmente construída de descrever e explicar o mundo. Nesse sentido, é importante que o professor ofereça possibilidades para o aluno participar ativamente do seu processo de construção do seu conhecimento, pois o conhecimento e o entendimento, inclusive o entendimento científico, são construídos quando os indivíduos se engajam socialmente em conversações e atividades sobre problemas e tarefas comuns.

Ao trabalhar a construção do conhecimento utilizando o ensino por investigação o professor pode utilizar atividades investigativas que requerem do aluno observação, reflexão, discussão e relato, o que dará ao seu trabalho as características de uma investigação científica. No momento em que o aluno expressa dúvida, discorda, apresenta alternativa, a compreensão sobre o conceito é ampliada de tal modo que o conhecimento possa ser reconstruído a partir da interação do grupo e não somente do aluno.

Todo o processo envolvendo professor e aluno, requer do aprendiz o desejo, a motivação para aprender, ou seja, a relação afetividade e aprendizagem caminham juntas para o sucesso de uma aprendizagem com significado, pois envolve, os aspectos afetivos e não somente os recursos elaborados para abordar o conteúdo, mas a motivação intrínseca para aprender.

A atividade docente dá unidade à dinâmica ensinoaprendizagem pelo processo de mediação entre o conhecimento a ser apreendido e a ação de apropriação desse conhecimento. Ao apropriar-se desse saber os alunos adquirem condições de enfrentar as exigências da vida em sociedade. E neste ponto reside um aspecto da importância social do saber escolar.

\section{REFERÊNCIAS}

ABEGG, I. \& BASTOS, F. P. Fundamentos para uma prática de ensino investigativa em Ciências Naturais e suas tecnologias: Exemplar de uma experiência em séries iniciais. Revista Electrónica de Enseñanza de lãs Ciências. v.4, n.3, 2005.

ALVES DE LIMA, V. \& RIBEIRO MARCONDES, M. E. Atividades experimentais no ensino de química. Reflexões de um grupo de professores a partir do tema eletroquímico. Revista Electrónica de Enseñanza de lãs Ciências, número extra. VII Congresso. p. 1 - 4. 2005.

BORGES, A. T. Novos rumos para o laboratório escolar de ciências. Caderno Brasileiro de Ensino de Física. Florianópolis, SC, v. 19, n. 3, p. 291-313, 2002.

BRASIL. Secretaria da Educação Fundamental. Parâmetros Curriculares Nacionais: Introdução Aos Parâmetros Curriculares Nacionais. 3. ed. Brasília: MEC/SEF. 2006. . Ministério da Educação. Secretaria de Educação Média e Tecnologia. Parâmetros Curriculares Nacionais: Ensino Fundamental, Brasília: Ministério da Educação, 1998.

CARVALHO, A. M. Fundamentos Teóricos e Metodológicos do Ensino por Investigação. Revista Brasileira de Pesquisa em 
Educação em Ciências, v. 18, n. 3, p. 765-794, 15 dez. 2018.

CARVALHO, A. M. P. e SASSERON, L. H. Alfabetização Cientifica: uma revisão bibliográfica. Investigações em Ensino de Ciências - V16(1), pp. 59-77, 2011.

CARVALHO, A.M P. Critérios Estruturantes para o Ensino das Ciências. In: CARVALHO, A.M.P. (Org.). Ensino de Ciências: unindo a pesquisa e a prática. Pioneira Thomsom Larning, São Paulo, p.1-17, 2004.

CHINN, C. A. and MALHOTRA, B.A. Epistemologically Authentic Inquiry in Schools: A Theoretical Framework for Evaluating Inquiry Tasks. Sci Ed. 86:175-218, 2002.

DELIZOICOV, D., ANGOTTI, J. A., PERNAMBUCO, M. M. Ensino de Ciências: fundamentos e métodos. (Coleção Docência em Formação). 3 ed., São Paulo: Cortez, 2009.

DOS SANTOS, V.; GALEMBECK, E. Sequência Didática com Enfoque Investigativo: Alterações Significativas na Elaboração de Hipóteses e Estruturação de Perguntas Realizadas por Alunos do Ensino Fundamental I. Revista Brasileira de Pesquisa em Educação em Ciências, v. 18, n. 3, p. 879-904, 15 dez. 2018.

DRIVER, R.; ASOKO, H.; LEACH, J. MORTIMER, e SCOTT, P. Construindo conhecimento científico na sala de aula. Química Nova na Escola № 9, 1999.

FERNANDES, C.C.M., A pesquisa em sala de aula como instrumento pedagógico: considerações para sua inclusão na prática pedagógica. Dialógicos Educ. R., v.2, n.2, 2011.

LOPES SCARPA, D. O papel da argumentação no Ensino de Ciências: Lições de um Workshop. Ensaio Pesquisa em Educação em Ciências, v. 17, 2015.

MAXIMO PEREIRA, M. Interações discursivas em pequeno grupo durante uma atividade investigativa sobre determinação da aceleração da gravidade. Ensaio Pesquisa em Educação em Ciências, v. 15, n. 2, 2013.

MOREIRA, M.A. O que é afinal Aprendizagem Significativa? Aula Inaugural do Programa de Pós-Graduação em Ensino de Ciências Naturais, Instituto de Física, Universidade Federal do Mato Grosso, Cuiabá, MT, 2012, aceito para publicação, Qurriculum, La Laguna, Espanha, 2012.

MORTIMER, E. F. Pressupostos epistemológicos para uma metodologia de ensino de química: mudança conceitual e perfil epistemológico. Química Nova, v. 15, n. 3, p.242249, 1992.

SANTOS, Wildson L. P. e MORTIMER, E. F.; Concepções de professores sobre contextualização social do ensino de química e ciências. In: 54 Reunião Anual da Sociedade Brasileira de Química, 22, 1999. Anais Poços de Caldas: Sociedade Brasileira de Química, 1999.

SANTOS, W. L. P.; Contextualização no Ensino de Ciências por Meio de Temas Cts em uma Perspectiva Crítica. Ciência \& Ensino, vol. 1, número especial, novembro de 2007
TRAZZI, P.S.S; BRASIL, E.D.F. Ensino por investigação: análise de uma atividade experimental em sala de aula de Biologia. Anais do XI Encontro Nacional de Pesquisa em Educação em Ciências - XI ENPEC. Universidade Federal de Santa Catarina, Florianópolis, SC, 2017.

WALDHELM, M.C.V. Como aprendeu ciências na educação básica quem hoje produz ciência?: o papel dos professores de ciências na trajetória acadêmica e profissional de pesquisadores da área de ciências naturais. Tese (PUC-RIO/EDUCAÇÃO). PUC. Rio de Janeiro, RJ. 2007.

Submissão: 17/05/2019

Aprovado para publicação: 23/05/2019 